\title{
JNK pathway and relative transcriptional factor were involved in ginsenoside Rh2- mediated G1 growth arrest and apoptosis in human lung adenocarcinoma A549 cells
}

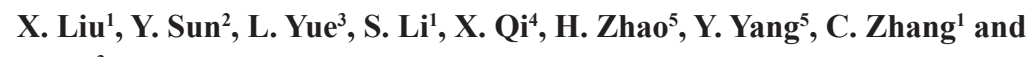
H. Yu $\mathbf{u}^{3}$

${ }^{1}$ Department of Biochemistry, Qiqihar Medical University, Heilongjiang, Qiqihar, China

${ }^{2}$ Department of Clinical Pathogenic Microorganism, Qiqihar Medical University, Heilongjiang, Qiqihar, China

${ }^{3}$ Department of Biology Genetics, Qiqihar Medical University, Heilongjiang, Qiqihar, China

${ }^{4}$ Department of Clinical Biochemistry, Qiqihar Medical University, Heilongjiang, Qiqihar, China

${ }^{5}$ School of Basic Medical Sciences, Qiqihar Medical University,

Heilongjiang, Qiqihar, China

Corresponding authors: C. Zhang / H. Yu

E-mail: cjzhang2005@163.com / yht422@126.com

Genet. Mol. Res. 15 (3): gmr.15039003

Received July, 21, 2016

Accepted August 1, 2016

Published September 19, 2016

DOI http://dx.doi.org/10.4238/gmr.15039003

Copyright $(C 2016$ The Authors. This is an open-access article distributed under the terms of the Creative Commons Attribution ShareAlike (CC BY-SA) 4.0 License

ABSTRACT. Ginsenoside Rh2 has been shown to have an antitumor effect on a wide range of cancers. A previous study has shown that ginsenoside Rh2 can inhibit the proliferation of the human lung adenocarcinoma A549 cell line in a dose-dependent manner by 
activating caspase- $8 / 3$ activity to promote apoptosis. However, the association of the JNK signaling pathways and transcription factors with ginsenoside Rh2 in the suppression of non-small cell lung cancer has not yet been reported. In this study, we found that ginsenoside Rh2 can activate the JNK/MAPKs signaling pathway and increase the phosphorylation and transcriptional activity of the transcription factors AP-1 and ATF2. Ginsenoside Rh2 also reduced the expression of transcription factors E2F1 and c-Myc. Furthermore, ginsenoside Rh2 affected the expression levels of cyclin D1 and the CDK4 protein, which are key regulatory factors of the G1/S cyclin-dependent kinase. The anti-proliferative and induced apoptotic effects of ginsenoside $\mathrm{Rh} 2$ on A549 cell provide evidence to support the application of traditional Chinese medicine to lung cancer treatment.

Key words: Ginsenoside Rh2; Human lung adenocarcinoma A549 cells; Cell proliferation; Transcription factors; MAPKs signaling pathway

\section{INTRODUCTION}

Ginseng is an important component of traditional Chinese medicine and has been used for culinary and medicinal purposes in China for thousands of years. A major active component of ginseng is ginsenoside $\mathrm{Rh} 2$ (G-Rh2 or Rh2), which exhibits a strong antitumor effect due to its low toxicity, small molecular weight, and lipid solubility. It is currently used as a central ingredient in various supplements for cancer adjuvant therapy.

Furthermore, G-Rh2 can act on multiple sites and target numerous molecules simultaneously. G-Rh2 has C20 spatial configuration (S/R). Most notably, 20(S)-G-Rh2 has a broad anti-tumor effect that can act on multiple organs. However, due to the genetic diversity of tumors, the underlying mechanisms governing the activity of G-Rh2 in various tumor cells differ greatly. The tumor suppressive ability of G-Rh2 is related to the inhibition of cell proliferation and metastasis, and induction of apoptosis . However, studies using different cell line models have reported conflicting data (Choi et al., 2011; Dong et al., 2011; Chung et al., 2013; Tang et al., 2013; Fatmawati et al., 2014; Guo et al., 2014; You et al., 2014a). We previously reported that G-Rh2 can inhibit the proliferation of human lung adenocarcinoma A549 cells as well as cause cell cycle arrest in the G1 phase in a dose-dependent manner. Furthermore, it activates NF- $\kappa$ B activity and promotes caspase-8/3 activation in A549 cells (Qi et al., 2011; Zhang et al., 2011; Gao et al., 2013; Yu et al., 2013).

Signaling pathways play an important role in regulating cellular function. The regulation of signaling pathways in tumor cells is frequently studied in cancer research because many of these pathways can initiate tumor cell cycle arrest, which inhibits tumor growth and promotes cell apoptosis. The mitogen-activated protein kinase (MAPK) signal transduction pathway is one of the key signaling pathways involved in cell proliferation, apoptosis, and differentiation (Kim et al., 2004). Several studies have demonstrated that MAPKs regulate apoptosis and cell survival by affecting mitochondrial membrane dynamics, the Bcl-2 family, and caspases (Lee and Shin, 2009; Seifert and Clarke, 2009; Xavier et al., 2009). Additionally, the ERK and p38 MAPK pathways are commonly activated and the JNK MAPK pathway

Genetics and Molecular Research 15 (3): gmr.15039003 
is commonly inhibited in tumor development (Liu et al., 2008; Li et al., 2009). Both JNK and $\mathrm{p} 38$ can affect the activity of numerous nuclear transcription factors, including c-Jun (a component of AP-1), NF-kB, ATF-2 (activating transcription factor 2), Elk-1 (Ets-like protein 1), and $\mathrm{p} 53$. Among the pro-apoptotic genes targeted by the NF- $\mathrm{KB}$ and Jun signaling pathways, FasL and TNF- $\alpha$ are frequently upregulated to induce the expression of respective ligands, which further activates caspase- 8 . In response, active caspase- 8 continues to induce other downstream caspases, such as caspase-3. As a result, the FasL-dependent programmed cell death pathway is activated. Therefore, proper regulation of MAPK signaling pathways may have significant clinical implications for cancer prevention, and may provide new targets and approaches for treating cancer.

Currently, the exact signaling pathways and targets mediating the antitumor properties of G-Rh2 in lung cancer have yet to be elucidated (Zhang et al., 2012; An et al., 2013; Kim et al., 2014). This study investigates the molecular pathways associated with G-Rh2 that regulate cell proliferation inhibition and apoptosis induction in the human lung cancer cell line A549. In this study, experiments were conducted on the MAPK pathways of ERK, JNK, and p38, as well as their respective downstream signal transduction pathways and transcription factors.

\section{MATERIAL AND METHODS}

\section{Materials}

20(S)-protopanaxadiol-3-O- $\beta$-D-glucopyranoside (20(S)-G-Rh2) was purchased from the National Institutes for Food and Drug Control (China). High-grade fetal bovine serum was purchased from Hyclone (USA). DMEM medium was purchased from Gibco (USA). Additionally, $0.25 \%$ trypsin in $0.02 \%$ EDTA was purchased from Gino Biomedical Technology (China). Antibodies targeting active caspase 3, pMAPK, and transcription factors were purchased from Cell Signaling (USA). Fluorescent Cy3-labeled secondary antibody and FITC-labeled secondary antibody were purchased from CW Biotechnology (China). DAPI was purchased from Roche (Switzerland). Anti- $\beta$-actin and anti-GAPDH antibodies were purchased from Santa Cruz (USA). HRP secondary antibody was purchased from Beijing Zhong Shan-Golden Bridge Biological Technology (China). RIPA lysis buffer was purchased from Applygen (China). Agarose powder was purchased from Sigma (USA), and DNA Ladder was purchased from BioLabs (USA).

\section{Cell culture}

The A549 cells were cultured in DMEM medium with $10 \%$ fetal bovine serum, $1 \%$ penicillin and streptomycin at $37^{\circ} \mathrm{C}$ with $5 \% \mathrm{CO}_{2}$. Cells were passaged and harvested with $0.25 \%$ trypsin in $0.02 \%$ EDTA. Cells in the proliferative phase were used for subsequent experiments.

\section{Cell cycle analysis by PI staining using flow cytometry}

We seeded $2 \mathrm{~mL} /$ well of A549 cells in six-well plates at a density of $1 \times 10^{5} / \mathrm{mL}$, and incubated for $18-24 \mathrm{~h}$ at $37^{\circ} \mathrm{C}$ and $5 \% \mathrm{CO}_{2}$. Medium was replaced with DMEM with $0.5 \%$ serum and incubated at $37^{\circ} \mathrm{C}$ for $12 \mathrm{~h}$ in order to allow the cells to enter the stationary phase.

Genetics and Molecular Research 15 (3): gmr.15039003 
The supernatant was then removed, and the cells were treated with either DMSO as a control or 20(S)-G-Rh2 for $24 \mathrm{~h}$. The cells were harvested and resuspended in $200 \mu \mathrm{L}$ of chilled PBS $\left(4^{\circ} \mathrm{C}\right)$. The cell solution was slowly added to $600 \mu \mathrm{L}$ of ice-cold absolute ethanol to generate a final concentration of $70 \%$ ethanol. The cells were fixed at $4^{\circ} \mathrm{C}$ overnight. The cells were washed with PBS twice after fixation and then treated with $100 \mu \mathrm{L}$ of RNase at $37^{\circ} \mathrm{C}$ for 15 min. Finally, $200 \mu \mathrm{L}$ of propidium iodide (PI) was added to the cell solution and incubated in the dark at room temperature for $5 \mathrm{~min}$. The percentages of cells in each phase of the cell cycle were determined by flow cytometry.

\section{Colony formation assay}

Agarose was prepared and added to the six-well plates at room temperature to form the lower layer. The A549 cells were harvested, and the cell number was determined. The cell suspension was mixed with the agarose solution by pipetting and was added on top of the lower layer. After the agarose gel solidified, the cells were cultured at $37^{\circ} \mathrm{C}$ with $5 \% \mathrm{CO}_{2}$. After 15 days, the colonies were stained overnight so that they would become visible to the naked eye. The colonies were counted and imaged under a microscope (Thermo, USA).

\section{ELISA for apoptotic cells}

Fragmented DNA from apoptotic cells form nucleosomes in the cytoplasm, which consist of histones and attached DNA strands. The ELISA method was used to detect these apoptotic cells. The cells were first lysed by high-speed centrifugation. The supernatant, which contains nucleosomes, was added to a micro-quantitative absorption plate containing histones, which bind to the nucleosomes. HRP-adjugated anti-DNA antibody was added to the plate to bind to the DNA in the nucleosomes. HRP-specific substrates were added for color development, and the plates were read in a microplate reader to determine the photometric absorbance.

\section{Western blot}

The cells were harvested and lysed. The proteins were isolated from the cells, and their concentrations were measured by using Bradford protein assay. Equal amounts of protein were run on an SDS-PAGE gel and transferred to a PVDF membrane. The membranes were blocked with 5-8\% skim milk and incubated with the primary antibody overnight at $4^{\circ} \mathrm{C}$. After washing the membrane three times for $5 \mathrm{~min}$ with PBS, the secondary antibodies were added and incubated at $37^{\circ} \mathrm{C}$ with slow shaking at $55 \mathrm{rpm}$ for $1 \mathrm{~h}$. The membranes were developed in a darkroom. The images were analyzed by the Bio-Rad Gel Doc gel imaging system and scanned for band density analysis by Quantity One. $\beta$-actin was used as a loading control, and the band intensity was calculated compared to assess the relative expression of the target protein and the control. The experiments were repeated three times.

\section{Fluorescence microscopy}

The cells were fixed with $95 \%$ ethanol for 10 min and permeabilized by PBS with

Genetics and Molecular Research 15 (3): gmr.15039003 
$0.1 \%$ TritonX-100 for 10 min with slow shaking. The primary antibodies were diluted 1:200 in PBST and added to the cells to incubate at $4{ }^{\circ} \mathrm{C}$ overnight. The fluorescent secondary antibodies were added to the cells at 1:200 in PBST. Finally, the cells were stained with DAPI at 1:500 at room temperature for $5 \mathrm{~min}$ before they were mounted on slides and imaged by inversion fluorescence microscope (Olympus IX81, Japan).

\section{Luciferase reporter assay}

The reporter plasmid of NF-kB-luc and AP-1-luc were gifts from the National Center for Human Genome Research. The plasmid extraction, cell transfection, and luciferase reporter assay were performed using the Plasmid Maxprep Kit, VigoFect, and Dual-Lucy Assay Kit, respectively, (Vigorous Biotechnology) following manufacturer protocols.

\section{Statistical analysis}

Data were presented as means $\pm \mathrm{SD}$, and differences between groups were detected using the Student $t$-test. Differences were considered statistically significant at $\mathrm{P}<0.05$.

\section{RESULTS}

\section{0(S)-G-Rh2 suppresses A549 cell growth}

A cell cycle analysis was performed in order to determine the effect of 20(S)-G-Rh2 on cell growth. We found that treating A459 cells with $20 \mu \mathrm{g} / \mathrm{mL}$ of 20 (S)-G-Rh2 for $24 \mathrm{~h}$ is sufficient to alter the distribution of cell cycle phases. 20(S)-G-Rh2 significantly increased the percentage of cells in the G0/G1 phase from 64.2 to $78.2 \%$. Furthermore, the proportion of cells in the S phase was significantly reduced from $13.1 \%$ in the control group to $24.3 \%$ in the treatment group. There was no significant difference in the proportions of cells in the G2/M phase between the two groups (Figure 1A). In addition, 20(S)-G-Rh2 significantly reduced the expression of cyclin-dependent protein kinase 4 (CDK4) and cyclin D1 (Figure 1B and C) and inhibited the colony formation of A549 cells by 2- to 5-fold (Figure 1D). These results suggest that 20(S)-G-Rh2 causes cell cycle arrest in the G1 phase by decreasing the level of regulatory factors that enable the start of the $\mathrm{S}$ phase.

\section{0(S)-G-Rh2 induces apoptosis in A549 cells}

During late apoptosis, nucleosomes were formed by endonuclease cleavage and consisted of several DNA fragments with a length of 180-200 base pairs. The activity of the apoptotic marker caspase-3 was detected by immunofluorescence. The cells treated with 30 $\mu \mathrm{g} / \mathrm{mL}$ of 20 (S)-G-Rh2 for $24 \mathrm{~h}$ had significantly enhanced caspase- 3 activity as indicated by the increased fluorescence intensity (Figure 2A). A western blot assay revealed an increase in expression of active caspase-3 following 20(S)-G-Rh2 treatment (Figure 2B and C). Furthermore, the amount of nucleosomes increased in the cells treated with 20(S)-G-Rh2, which is consistent with the apoptotic nuclear morphology observed in these cells (Figure 2D). These results suggest that 20(S)-G-Rh2 promotes apoptosis by increasing caspase- 3 activity and inducing DNA fragmentation.

Genetics and Molecular Research 15 (3): gmr.15039003 
A

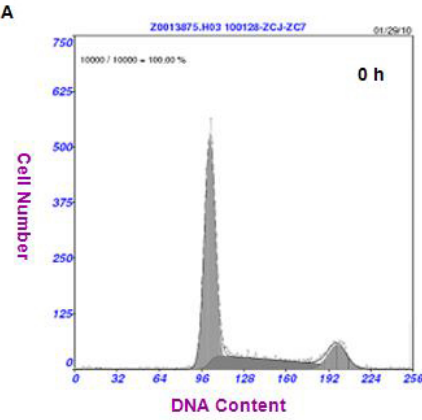

B

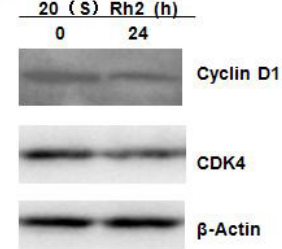

c

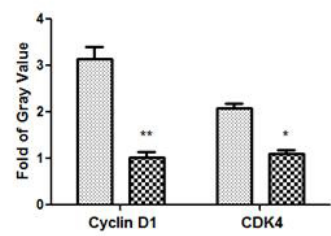

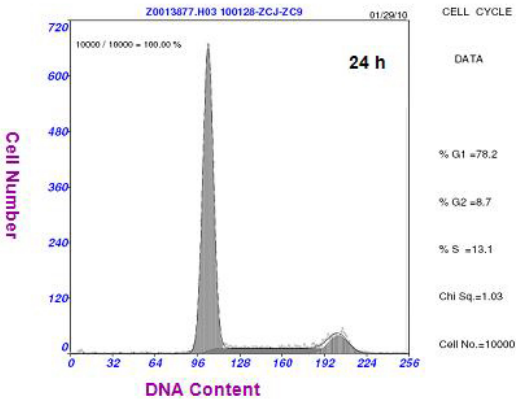

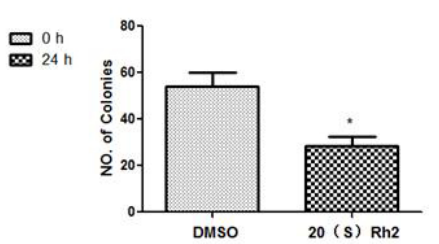

Figure 1. 20(S)-G-Rh2 inhibits cell proliferation in A549. A. Effect of $20 \mu \mathrm{g} / \mathrm{mL} 20$ (S)-G-Rh2 for 24 h on cell cycle distribution. DNA was stained with propidium iodide (PI) and assayed by flow cytometry. B. Effect of incubating cells with $20 \mu \mathrm{g} / \mathrm{mL} 20$ (S)-G-Rh2 for $24 \mathrm{~h}$ on the expression level of CDK4 and Cyclin D1. C. Histogram analysis of the gray value. D. Effect of $20 \mu \mathrm{g} / \mathrm{mL} 20$ (S)-G-Rh2 on colony formation. Values represent the mean $\pm \mathrm{SD}$ of three determinations from separate experiments. *Significantly different from the control at $\mathrm{P}<0.05$. **Significantly different from the control at $\mathrm{P}<0.01$.

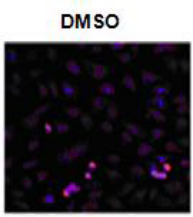

C

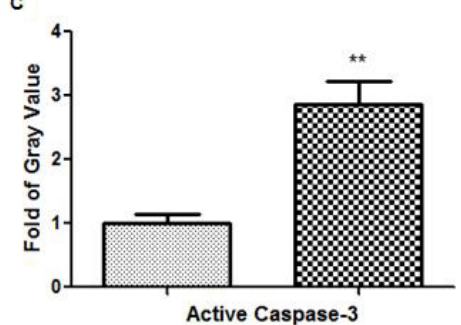

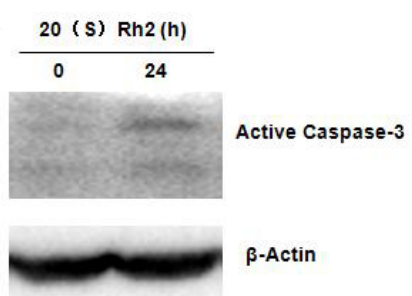

D

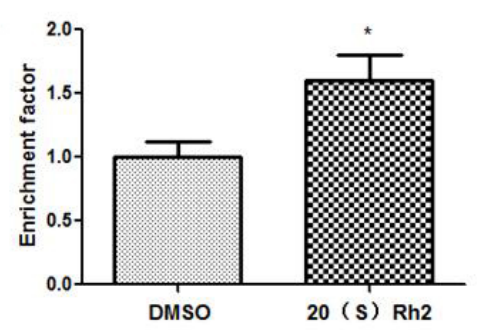

Figure 2. 20(S)-G-Rh2 mediates A549 apoptosis by regulating caspase-3. A. Immunofluorescence (200X) analysis of caspase-3 activity of A549 after 20(S)-G-Rh2 $(30 \mu \mathrm{g} / \mathrm{mL})$ treatment for $24 \mathrm{~h}$. B. Western blot analysis of caspase-3 expression level. C. Histogram analysis of the gray value. D. A549 apoptosis levels were analyzed by ELISA after $20(\mathrm{~S})-\mathrm{G}-\mathrm{Rh} 2(30 \mu \mathrm{g} / \mathrm{mL})$ treatment. Values represent the mean $\pm \mathrm{SD}$ of three determinations from separate experiments. *Significantly different from DMSO at $\mathrm{P}<0.05$. **Significantly different from the control at P < 0.01. DMSO: A549 with DMSO; 20(S)-G-Rh2: A549 with DMSO and 30- $\mu \mathrm{g} / \mathrm{mL} 20$ (S)-G-Rh2. 


\section{0(S)-G-Rh2 regulates the activity and expression of multiple transcription factors}

Protein expression level determines whether transcription factors such as ATF2, E2F1, and c-Myc regulate cell proliferation and apoptosis in an oncogenic or tumor suppressive manner. Previous data from our laboratory demonstrated that E2F1 and c-Myc are highly expressed in lung adenocarcinoma. In this study, we found that the protein expression of transcription factors E2F1 and c-Myc were significantly reduced in A549 cells that had been treated with $20 \mu \mathrm{g} / \mathrm{mL}$ of $20(\mathrm{~S})-\mathrm{G}-\mathrm{Rh} 2$ for $24 \mathrm{~h}$, whereas the phosphorylation levels of transcription factor ATF2 were upregulated-(Figure 3A-D). Additionally, after 0.5$1 \mathrm{~h}$ treatment with 20(S)-G-Rh2, the A549 cells exhibited enhanced nuclear NF-кBp65 immunofluorescent intensity (data not shown). In contrast, the nuclear immunofluorescent intensity of phosphorylated c-Jun did not change following the same treatment. However, the fluorescent intensity of c-Jun increased significantly in the nuclear of cells treated for 2-6 $\mathrm{h}$ in a time-dependent manner (Figure 3E). Furthermore, treating the cells with $20 \mu \mathrm{g} / \mathrm{mL}$ of 20(S)-G-Rh2 for $24 \mathrm{~h}$ significantly increased the relative luciferase values of both NF-kB-luc (data not shown) and the AP-1-luc reporter gene as compared to the control (Figure 3F). These results suggest that $20(\mathrm{~S})-\mathrm{G}-\mathrm{Rh} 2$ activates the transcription of both transcription factor NF- $\mathrm{KB}$ and AP-1 and thereby inhibit cell proliferation and induce apoptosis in the A549 cells.
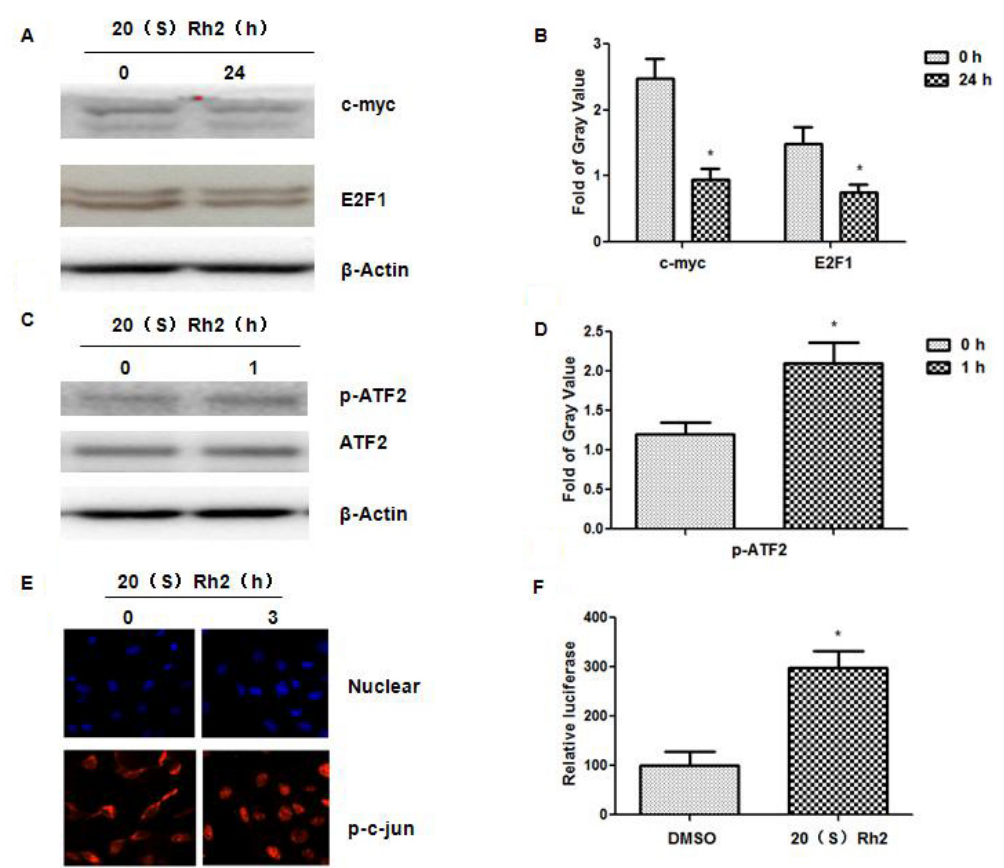

Figure 3. 20(S)-G-Rh2 regulation of the transcriptional activity of multiple transcription factors. A. Western blot analysis of E2F1 and c-myc expression level of A549 after 20(S)-G-Rh2 $(20 \mu \mathrm{g} / \mathrm{mL})$ treatment for $24 \mathrm{~h}$. B. Histogram analysis of the gray value. C. Western blot analysis of ATF2 expression level of A549 after 20(S)-G-Rh2 $(20 \mu \mathrm{g} / \mathrm{mL})$ treatment for $1 \mathrm{~h}$. D. Histogram analysis of the gray value. E. Immunofluorescence analysis of the phosphorylation and nuclear translocation of transcription factor AP-1 of A549 after 20(S)-G-Rh2 (20 $\mu \mathrm{g} / \mathrm{mL})$ treatment for $3 \mathrm{~h}$. F. Luciferase reporter assay of transcription factors AP-1-luc in treated and untreated A549 cells. Values are reported as means $\pm \mathrm{SD}$ of three determinations from separate experiments. *Significantly different from the control or the DMSO control at P < 0. 05. DMSO: A549 with DMSO; 20(S)-G-Rh2: A549 with DMSO and $20 \mu \mathrm{g} / \mathrm{mL} 20(\mathrm{~S}) \mathrm{Rh} 2$. 


\section{0(S)-G-Rh2 activates JNK and ERK signaling pathways}

To further confirm that 20(S)-G-Rh2 regulates the ERK and JNK signal transduction pathways by targeting specific proteins, the expression levels of protein associated with MAPK signal transduction pathways were determined by western blot and immunofluorescence assay. Treatment with $20 \mu \mathrm{g} / \mathrm{mL}$ of $20(\mathrm{~S})-\mathrm{G}-\mathrm{Rh} 2$ affected neither the phosphorylation nor the expression level of p38 with respect to that of the control. Similarly, the expression levels of ERK and JNK were unchanged. However, the phosphorylation of both ERK and JNK significantly increased upon exposure to $20(\mathrm{~S})-\mathrm{G}-\mathrm{Rh} 2$. The fluorescence intensity of ERK $1 / 2$ (FITC) and p-JNK (Cy3) increased in the A549 cells 3-4 h after treatment, which indicates that 20(S)-G-Rh2 induces the activation of the ERK1/2 and JNK signaling pathways. These findings were validated by western blot (Figure 4).

A

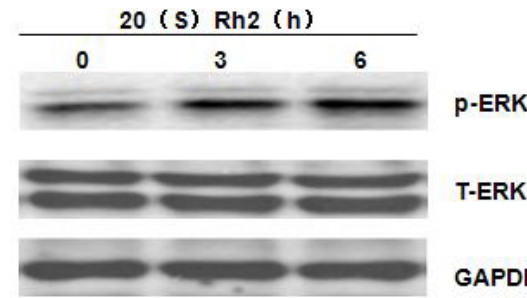

C

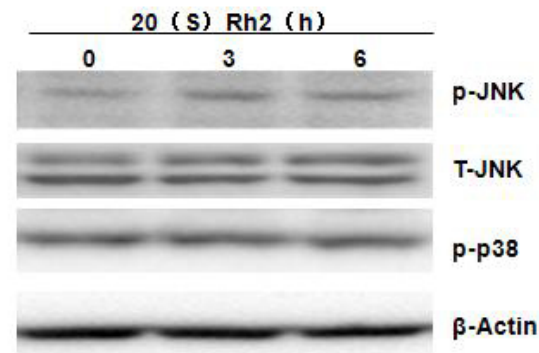

E

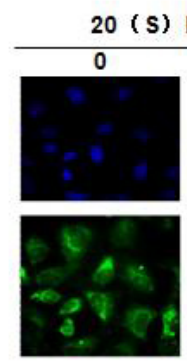

B

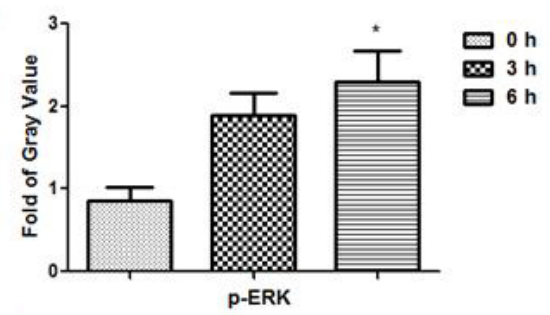

D

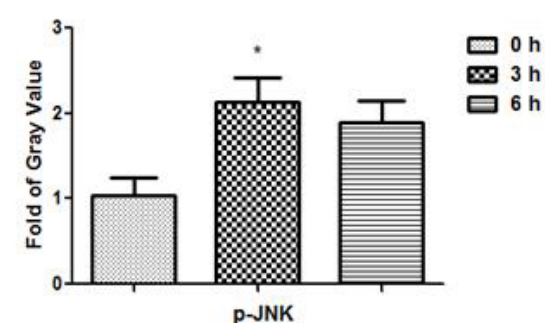

$\mathbf{F}$

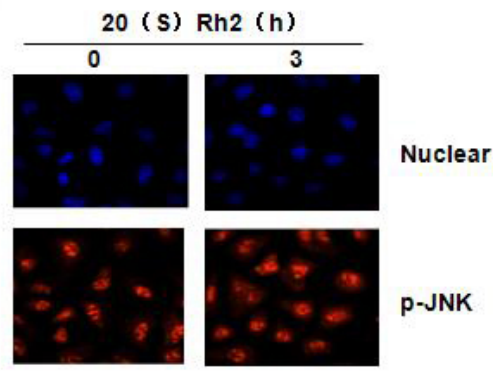

Figure 4. 20(S)-G-Rh2 activates ERK1/2 and the JNK signaling pathway. A. C. Western blot analysis of related molecules in the MAPK signaling pathways of A549 after 20(S)-G-Rh2 $(20 \mu \mathrm{g} / \mathrm{mL})$ treatment; B. D. Histogram analysis of the gray value; E. F. Immunofluorescence analysis of the expression and nucleus translocation of related molecules in the MAPK signaling pathways of A549 after 20(S)-G-Rh2 $(20 \mu \mathrm{g} / \mathrm{mL})$ treatment. Values are reported as means $\pm \mathrm{SD}$ of three determinations from separate experiments. *Significantly different from the control at $\mathrm{P}<0.05$. 


\section{DISCUSSION}

During the G1 phase, cyclin D1 forms a complex with CDK4 that is considered the key positive regulator of the G1/S phase. The main substrates of CDK activation are the $\mathrm{Rb}$ protein family (pRb, p107, and p103) and E2F (Imai et al., 2004). Li et al. explored the role of antisense RNA gene therapy in targeting cyclin D1 in lung cancer, and they found that knockingdown cyclin D1 can induce apoptosis in A549 cells, which may be associated with the reduced expression of intracellular pRb, E2F1, VEGF, MMP- 2, and MMP-9 (Li et al., 2011). As a nuclear transcription factor that is widely involved in cell cycle regulation, E2F1 can promote progression from the $\mathrm{G} 1$ phase to the $\mathrm{S}$ phase, thereby accelerating the cell proliferation cycle. In cancer cells, an overexpression of E2F1 continuously stimulates the transcription of oncogenic c-Myc (Warner et al., 2003). As an active transcription factor, c-Myc can activate positive regulators of the cell cycle, such as CDK4 and cyclin A, thereby promoting transition from the G1 phase to the S phase. As a result, c-Myc induces cell proliferation and eventually causes both hyperproliferation and malignant transformation. Accordingly, numerous studies have demonstrated that E2F1 and c-Myc are often overexpressed in lung cancer tissue samples, suggesting that dysregulation of E2F1 and c-Myc plays an important role in promoting the occurrence and development of lung cancer (Warner et al., 2003; Huang et al., 2007; Li et al., 2007). Salon et al. reported that overexpressed E2F1 in lung cancer can activate FasLmediated apoptosis (Salon et al., 2006); however, active caspase-8 is also necessary for the activation of caspase-3, which eventually leads to lung adenocarcinoma regression.

Studies have shown that 20(S)-G-Rh2 can significantly reduce the phosphorylation of $\mathrm{pRb}$ as well as the transcriptional activity of E2F by affecting cyclin D1 and CDK4/6 in order to regulate G1/S arrest, which leads to apoptosis in liver cancer and breast cancer cells (Choi et al., 2009). Our results indicate that 20(S)-G-Rh2 can inhibit A549 cell proliferation and induce cell cycle arrest in the G1 phase in a dose-dependent manner. The inhibitory mechanism is associated with decreased expression levels of CDK4/cyclin D1 and E2F1 as well as reduced A549 cell colony formation, which is consistent with previous reports that 20(S)-G-Rh2 helps control regulatory proteins related to the G1 phase, such as cyclin D1, cyclin E, CDK6, and pRb (Cheng et al., 2005).

An overexpression of ERK may play a role in the tumorigenesis and development of non-small cell lung cancer (Tao et al., 2006). Studies have shown that glucocorticoids can reduce the activities of CDK2, CDK4, cyclin D, E2F, and Myc by decreasing ERK, thereby arresting cancer cells at the G1/G0 phase and inhibiting cancer cell growth (Greenberg et al., 2002a). Our results demonstrate that ERK phosphorylation increases after 20(S)-GRh2 treatment, which inconsistent with $20(\mathrm{~S})-\mathrm{G}-\mathrm{Rh} 2$ inhibiting ERK activation and cell proliferation. Enhanced nuclear and cytoplasmic staining of active p38, which is essential for apoptosis induced by anticancer drugs (Ghatan et al., 2000), was observed in samples taken from patients with non-small cell lung cancer (Greenberg et al., 2002b). Active p38 stimulates pathways that result in enhanced expression of c-Myc (Stoneley et al., 2000), phosphorylation of p53, and activation of c-Jun (Stepniak et al., 2006). Our results indicate that 20(S)-G-Rh2 had negligible effects on the level of phosphorylated p38, suggesting that the apoptotic effect of 20 (S)-G-Rh2 is not mediated by p38 signaling pathways.

JNK activation increases the expression and activity of downstream targeted genes through transcription-dependent and independent manners and promotes cell apoptosis. Active JNK translocates from the cytoplasm to the nucleus and phosphorylates a series of

Genetics and Molecular Research 15 (3): gmr.15039003 
transcription factors, including c-Jun, c-Fos, and Elk-1, thereby regulating the expression of target apoptotic genes (Pan et al., 2007). Using c-Jun as a substrate, JNK improves the transcriptional activity of AP-1 (Dong et al., 2001). In addition, JNK can bind and phosphorylate p53, thereby enhancing its transcriptional activity. Consequently, p53 inhibits the malignant transformation of cells and promotes apoptosis in these cells. After translocating to the nucleus, JNK activates transcription factors and FasL expression, which then activates caspase- 8 and downstream caspases, such as caspase-3. The initiation of programmed cell death eventually leads to cell apoptosis and regulates cell proliferation and apoptosis (Soh et al., 2001). Our results indicate that 20(S)-G-Rh2 increases caspase- 3 activity as well as DNA breakage and JNK phosphorylation, which is consistent with the hypothesis that $20(\mathrm{~S})-\mathrm{G}-\mathrm{Rh} 2$ promotes JNK activation and induces apoptosis.

The effect of AP-1 on cell growth appears to be primarily mediated by regulators of the cell cycle, such as cyclin D, cyclin A, p53, p21Cip, p16INK4a, and p19Arf (Eferl and Wagner, 2003). Whether AP-1 promotes or inhibits the cell cycle depends on the ratio of each subunit of AP-1 in the cells as well as the cell type and microenvironment. Oncogene Fra-1, a member of the FOS family and part of the AP-1 transcription complex, is involved in cell proliferation, invasion, and division (Salon et al., 2006). Our results indicate that 20(S)-G-Rh2 significantly increased the phosphorylation of c-Jun, which is consistent with our hypothesis that JNK activation induced by 20 (S)-G-Rh2 can further promote the AP-1 signaling pathway and, ultimately, apoptosis in A549 cells.

Our study found that 20(S)-G-Rh2 activates both the ERK1/2 and JNK signaling pathways. It can also induce cell cycle arrest at G1/G0 by inhibiting CDK4, cyclin D1, E2F1, and c-Myc. It has previously been shown that $20(\mathrm{~S})-\mathrm{G}-\mathrm{Rh} 2$ enhances the transcriptional activity of transcription factor NF- $\kappa \mathrm{B}$ and induces the transcription of TNF- $\alpha$, which is involved in apoptosis regulation and eventually leads to the apoptosis of lung cancer cells (Yu et al., 2013). Knocking down cyclin D1 significantly inhibits the proliferation, invasion, and metastasis of A549 cells (Li et al., 2011). Thus, inhibiting the cyclin D1expression might be a novel approach for treating lung cancer. Additionally, E2F1 and c-Myc influence the tumorigenesis and development of many tumors, as either oncogenes or tumor suppressors. On the other hand, they are housekeeping genes that regulate the proliferation, differentiation, and metabolism of normal cells. It remains unclear how the regulatory network of E2F1 and c-Myc differ under various physiological and pathological conditions. It is possible that the targeted molecules or their quantities, or both, are altered during tumorigenesis. Further study is needed to elucidate the exact mechanism.

It is commonly accepted that oncogenes, such as E2F1 and c-Myc, are only involved in the malignant transformation of cancer cells when they are unable to control tumor progression, which is subject to the specificity of different tumor types and other factors yet to be identified. Our current study found that 20(S)-G-Rh2 can inhibit A549 cell colony formation and can prevent cancer cell transformation. A major goal for cancer research is that, with personalized examinations of the expression profiles of targeted molecules such as E2F1 and c-Myc in individual cancer patients, clinicians can more effectively evaluate cancer progression and prognosis, and provide better treatment guidance. Thus, it is necessary to further study the roles of JNK and ERK pathway activation and their downstream transcription factors in 20(S)-G-Rh2-mediated lung cancer inhibition. It is imperative to perform a more thorough examination into how $20(\mathrm{~S})-\mathrm{G}-\mathrm{Rh} 2$ regulates multiple signal transduction molecules both within and outside the nucleus and ultimately regulates cell apoptosis, inflammation, and

Genetics and Molecular Research 15 (3): gmr.15039003 
cell proliferation. Future studies should explore the active site and pathway of 20 (S)-G-Rh2 as well as its influence on oncogene and tumor suppressors. The effect of $20(\mathrm{~S})-\mathrm{G}-\mathrm{Rh} 2$ on different tumor cells and the resulting differentiation should also be further studied. Although a handful of studies have demonstrated that 20(S)-G-Rh2 can alter the activity of the MAPK, ERK, and TGF- $\beta$ signaling pathways in tumor cells, it is still unclear if these pathways mediate the antitumor mechanism of 20(S)-G-Rh2 in preventing invasion and metastasis. Therefore, a detailed and systematic study is still essential to investigate the molecular mechanism of the tumor-inhibitory effect of $20(\mathrm{~S})-\mathrm{G}-\mathrm{Rh} 2$ in order to provide more detailed evidence for clinical application.

\section{Conflicts of interest}

The authors declare no conflict of interest.

\section{ACKNOWLEDGMENTS}

Research supported by grants from the Natural Science Foundation of Heilongjiang Province (\#ZD2016020) and the Foundation of Qiqihar Medical University.

\section{REFERENCES}

An IS, An S, Kwon KJ, Kim YJ, et al. (2013). Ginsenoside Rh2 mediates changes in the microRNA expression profile of human non-small cell lung cancer A549 cells. Oncol. Rep. 29: 523-528 10.3892/or.2012.2136.

Cheng CC, Yang SM, Huang CY, Chen JC, et al. (2005). Molecular mechanisms of ginsenoside Rh2-mediated G1 growth arrest and apoptosis in human lung adenocarcinoma A549 cells. Cancer Chemother. Pharmacol. 55: 531-540. http:// dx.doi.org/10.1007/s00280-004-0919-6

Choi S, Kim TW and Singh SV (2009). Ginsenoside Rh2-mediated G1 phase cell cycle arrest in human breast cancer cells is caused by p15 Ink4B and p27 Kip1-dependent inhibition of cyclin-dependent kinases. Pharm. Res. 26: 2280-2288 http://dx.doi.org/10.1007/s11095-009-9944-9.

Choi S, Oh JY and Kim SJ (2011). Ginsenoside Rh2 induces Bcl-2 family proteins-mediated apoptosis in vitro and in xenografts in vivo models. J. Cell. Biochem. 112: 330-340 http://dx.doi.org/10.1002/jcb.22932.

Chung KS, Cho SH, Shin JS, Kim DH, et al. (2013). Ginsenoside Rh2 induces cell cycle arrest and differentiation in human leukemia cells by upregulating TGF- $\beta$ expression. Carcinogenesis 34: 331-340 http://dx.doi.org/10.1093/ carcin/bgs341.

Dong C, Davis RJ and Flavell RA (2001). Signaling by the JNK group of MAP kinases. c-jun N-terminal Kinase. J. Clin. Immunol. 21: 253-257. http://dx.doi.org/10.1023/A:1010975124110

Dong H, Bai LP, Wong VK, Zhou H, et al. (2011). The in vitro structure-related anti-cancer activity of ginsenosides and their derivatives. Molecules 16: 10619-10630 http://dx.doi.org/10.3390/molecules161210619.

Eferl R and Wagner EF (2003). AP-1: a double-edged sword in tumorigenesis. Nat. Rev. Cancer 3: 859-868. http://dx.doi. org $/ 10.1038 / \mathrm{nrc1} 209$

Fatmawati S, Ersam T, Yu H, Zhang C, et al. (2014). 20(S)-Ginsenoside Rh2 as aldose reductase inhibitor from Panax ginseng. Bioorg. Med. Chem. Lett. 24: 4407-4409 http://dx.doi.org/10.1016/j.bmcl.2014.08.009.

Gao H, Sun Y, Yu HT and Zhang CJ (2013). Mechanism of Ginsenoside Rh2 Inhibit Non-small Cell Lung Cancer. $A d v$. Mat. Res. 749: 167-171 http://dx.doi.org/10.4028/www.scientific.net/AMR.749.167.

Ghatan S, Larner S, Kinoshita Y, Hetman M, et al. (2000). p38 MAP kinase mediates bax translocation in nitric oxideinduced apoptosis in neurons. J. Cell Biol. 150: 335-347. http://dx.doi.org/10.1083/jcb.150.2.335

Greenberg AK, Hu J, Basu S, Hay J, et al. (2002a). Glucocorticoids inhibit lung cancer cell growth through both the extracellular signal-related kinase pathway and cell cycle regulators. Am. J. Respir. Cell Mol. Biol. 27: 320-328. http://dx.doi.org/10.1165/rcmb.4710

Greenberg AK, Basu S, Hu J, Yie TA, et al. (2002b). Selective p38 activation in human non-small cell lung cancer. Am. J. Respir. Cell Mol. Biol. 26: 558-564. http://dx.doi.org/10.1165/ajrcmb.26.5.4689

Genetics and Molecular Research 15 (3): gmr.15039003 
Guo XX, Li Y, Sun C, Jiang D, et al. (2014). p53-dependent Fas expression is critical for Ginsenoside Rh2 triggered caspase-8 activation in HeLa cells. Protein Cell 5: 224-234 http://dx.doi.org/10.1007/s13238-014-0027-2.

Huang CL, Liu D, Nakano J, Yokomise H, et al. (2007). E2F1 overexpression correlates with thymidylate synthase and survivin gene expressions and tumor proliferation in non small-cell lung cancer. Clin. Cancer Res. 13: 6938-6946. http://dx.doi.org/10.1158/1078-0432.CCR-07-1539

Imai MA, Oda Y, Oda M, Nakanishi I, et al. (2004). Overexpression of E2F1 associated with LOH at RB locus and hyperphosphorylation of RB in non-small cell lung carcinoma. J. Cancer Res. Clin. Oncol. 130: 320-326. http:// dx.doi.org/10.1007/s00432-003-0538-3

Kim BC, van Gelder H, Kim TA, Lee HJ, et al. (2004). Activin receptor-like kinase-7 induces apoptosis through activation of MAPKs in a Smad3-dependent mechanism in hepatoma cells. J. Biol. Chem. 279: 28458-28465. http://dx.doi. org/10.1074/jbc.M313277200

Kim MJ, Yun H, Kim DH, Kang I, et al. (2014). AMP-activated protein kinase determines apoptotic sensitivity of cancer cells to ginsenoside-Rh2. J. Ginseng Res. 38: 16-21. http://dx.doi.org/10.1016/j.jgr.2013.11.010

Lee YA and Shin MH (2009). Mitochondrial respiration is required for activation of ERK1/2 and caspase-3 in human eosinophils stimulated with hydrogen peroxide. J. Investig. Allergol. Clin. Immunol. 19: 188-194.

Li DD, Wang LL, Deng R, Tang J, et al. (2009). The pivotal role of c-Jun NH2-terminal kinase-mediated Beclin 1 expression during anticancer agents-induced autophagy in cancer cells. Oncogene 28: 886-898 http://dx.doi. org/10.1038/onc.2008.441.

Li QZ, Jiang YE, Zhang SM, Mao YR, et al. (2007). Expressions and implications of p65, c-myc and p73 proteins in nonsmall cell lung cancer. China J. Cancer Prev. Treat. 14: 324-327.

Liu W, Liang Q, Balzar S, Wenzel S, et al. (2008). Cell-specific activation profile of extracellular signal-regulated kinase 1/2, Jun N-terminal kinase, and p38 mitogen-activated protein kinases in asthmatic airways. $J$ Allergy Clin Immunol. 121: 893-902. e2. http://dx.doi.org/10.1016/j.jaci.2008.02.004

Li ZL, Shao SH, Xie SY, Yue Z, et al. (2011). Anti-sense nucleic acid of CyclinD1 induces apoptosis of lung adenocarcinoma cancer cell A549. Sheng Li Xue Bao 63: 261-266.

Pan J, Zhao YX, Wang ZQ, Jin L, et al. (2007). Expression of FasL and its interaction with Fas are mediated by c-Jun N-terminal kinase (JNK) pathway in 6-OHDA-induced rat model of Parkinson disease. Neurosci. Lett. 428: 82-87. http://dx.doi.org/10.1016/j.neulet.2007.09.032

Qi XD, Hou JC, Yu HT and Zhang CJ (2011). 20(S)-Ginsenoside-Rh2 and 20(R)-Ginsenoside-Rh2 activate IkappaB phosphorylation expression in human lung adeno carcinoma A549 cells. Adv. Mat. Res. 268-270: 1205-1210 http:// dx.doi.org/10.4028/www.scientific.net/AMR.268-270.1205.

Salon C, Eymin B, Micheau O, Chaperot L, et al. (2006). E2F1 induces apoptosis and sensitizes human lung adenocarcinoma cells to death-receptor-mediated apoptosis through specific downregulation of c-FLIP(short). Cell Death Differ. 13: 260-272. http://dx.doi.org/10.1038/sj.cdd.4401739

Seifert A and Clarke PR (2009). p38alpha- and DYRK1A-dependent phosphorylation of caspase-9 at an inhibitory site in response to hyperosmotic stress. Cell. Signal. 21: 1626-1633 http://dx.doi.org/10.1016/j.cellsig.2009.06.009.

Soh JW, Mao Y, Liu L, Thompson WJ, et al. (2001). Protein kinase G activates the JNK1 pathway via phosphorylation of MEKK1. J. Biol. Chem. 276: 16406-16410. http://dx.doi.org/10.1074/jbc.C100079200

Stepniak E, Ricci R, Eferl R, Sumara G, et al. (2006). c-Jun/AP-1 controls liver regeneration by repressing p53/p21 and p38 MAPK activity. Genes Dev. 20: 2306-2314. http://dx.doi.org/10.1101/gad.390506

Stoneley M, Chappell SA, Jopling CL, Dickens M, et al. (2000). c-Myc protein synthesis is initiated from the internal ribosome entry segment during apoptosis. Mol. Cell. Biol. 20: 1162-1169. http://dx.doi.org/10.1128/MCB.20.4.11621169.2000

Tang XP, Tang GD, Fang CY, Liang ZH, et al. (2013). Effects of ginsenoside Rh2 on growth and migration of pancreatic cancer cells. World J. Gastroenterol. 19: 1582-1592 http://dx.doi.org/10.3748/wjg.v19.i10.1582.

Tao WP, Wang ZW, Ge W and Xie YS (2006). Expression of extracelluar signal-regulated kinase in nonsmall cell lung cancer and its clinical significance. J. Hubei Med. Univ. 14: 568-569.

Warner KA, Crawford EL, Zaher A, Coombs RJ, et al. (2003). The c-myc x E2F-1/p21 interactive gene expression index augments cytomorphologic diagnosis of lung cancer in fine-needle aspirate specimens. J. Mol. Diagn. 5: 176-183. http://dx.doi.org/10.1016/S1525-1578(10)60470-9

Xavier CP, Lima CF, Fernandes-Ferreira M and Pereira-Wilson C (2009). Salvia fruticosa, Salvia officinalis, and rosmarinic acid induce apoptosis and inhibit proliferation of human colorectal cell lines: the role in MAPK/ERK pathway. Nutr. Cancer 61: 564-571 http://dx.doi.org/10.1080/01635580802710733.

You Z, Chen D, Wei Q, Zhao L, et al. (2014a). Ginsenoside Rh2 inhibits proliferation and promotes apoptosis of leukemia KG1- $\alpha$ cells. Xibao Yu Fenzi Mianyixue Zazhi 30: 565-568.

Genetics and Molecular Research 15 (3): gmr.15039003 
You ZM, Zhao L, Xia J, Wei Q, et al. (2014b). Down-regulation of phosphoglucose isomerase/autocrine motility factor enhances gensenoside Rh2 pharmacological action on leukemia KG1 $\alpha$ cells. Asian Pac. J. Cancer Prev. 15: 10991104. http://dx.doi.org/10.7314/APJCP.2014.15.3.1099

Yu HT, Hou JC, Qi XD, Shi Y, et al. (2013). 20 (S)-Ginsenoside-Rh2 Induces Apoptosis in Human Lung Adenocarcinoma A549 cells by Activating NF-kB Signaling Pathway. J. Pure APPL Microbiol. 7: 287-294.

Zhang C, Yu H and Hou J (2011). Effects of 20 (S) -ginsenoside Rh2 and 20 (R) -ginsenoside Rh2 on proliferation and apoptosis of human lung adenocarcinoma A549 cells. Zhongguo Zhongyao Zazhi 36: 1670-1674.

Zhang J, Lu M, Zhou F, Sun H, et al. (2012). Key role of nuclear factor- $\kappa B$ in the cellular pharmacokinetics of adriamycin in MCF-7/Adr cells: the potential mechanism for synergy with 20(S)-ginsenoside Rh2. Drug Metab. Dispos. 40: 1900-1908 http://dx.doi.org/10.1124/dmd.112.045187.

Genetics and Molecular Research 15 (3): gmr.15039003 